\title{
Relação entre área basal e a precipitação efetiva em um fragmento de mata atlântica na zona da mata norte mineira
}

\author{
Camila Soares Braga ${ }^{1}$ \\ Vitor Hugo Breda Barbosa ${ }^{2}$ \\ Carlos Eduardo Gazzola ${ }^{3}$ \\ Herly Carlos Teixeira Dias ${ }^{4}$ \\ 1,2,3,4,Universidade Federal de Viçosa - UFV \\ Cep: 36570-000 - Viçosa - MG, Brasil \\ 1 camilasbraga@yahoo.com.br; ${ }^{2}$ vitorhbb@yahoo.com.br; \\ ${ }^{3}$ cadugazzola_10@ hotmail.com; ${ }^{4}$ herly@ufv.br.
}

\begin{abstract}
The objective of this research was to analyze relationship between the basal area and precipitation it executes of rain water in Reserva Florestal e Ecológica Mata do Paraíso located in Atlantic forest, Minas Gerais-Brazil. During one year it was measured the drainage for the stem of the trees and of the interns precipitation, totaling 15 collections in the rainy period from January to May and October to December of 2007 four collections in the drought period, totaling 19 collections. Inside the forest three experimental portions were demarcated, with $625 \mathrm{~m}^{2}$ area, which is in initial apprenticeship of regeneration. In agreement with the observed results, there isn't direct relationship among the effective precipitation and the basal area of the portions.
\end{abstract}

Key-words: basal area, effective precipitation, Atlantic forest

Resumo. O objetivo desta pesquisa foi analisar relação entre a área basal e precipitação efetiva de água de chuva, de uma área localizada no fragmento florestal remanescente de Mata Atlântica, Reserva Florestal e Ecológica Mata do Paraíso, localizada no Município de Viçosa, Zona da Mata do Estado de Minas Gerais. No período de um ano foram medidos os escoamentos pelo tronco das árvores e da precipitação interna, totalizando 15 coletas no período chuvoso que compreendeu de Janeiro à Maio e Outubro a Dezembro e quatro coletas no período de estiagem, compreendido entre Junho a Setembro de 2007, totalizando19 coletas. No interior da floresta foram demarcadas três parcelas experimentais, com $625 \mathrm{~m}^{2}$ de área, a qual se encontra em estagio inicial de regeneração. Para determinação do escoamento pelo tronco foram instalados dispositivos de espuma de poliuretano em 18 árvores localizadas dentro da parcelas, e para a quantificação da precipitação interna, foram utilizados 25 pluviômetros em cada parcela. A precipitação efetiva foi calculada somando-se a precipitação interna e escoamento pelo tronco. Calculando-se a media da precipitação efetiva das chuvas nesse período, verificou-se que não há relação direta entre a área basal das parcelas e a precipitação efetiva. Para as parcelas 1,2,3 foi encontrada uma área basal de $2,2087 \mathrm{~m}^{2} ; 1,3293 \mathrm{~m}^{2} ; 3,7721 \mathrm{~m}^{2}$ respectivamente, e a precipitação efetiva nas três parcelas foram: $62,5 \mathrm{~mm} ; 58,8 \mathrm{~mm} ; 61,1 \mathrm{~mm}$ respectivamente. De acordo com os resultados observados conclui-se que não existe relação direta entre a precipitação efetiva e a área basal das parcelas no período avaliado.

Palavras-chave: área basal, precipitação efetiva, Mata Atlantica.

\section{Introdução}

A precipitação é a água proveniente do vapor de água da atmosfera depositada na superfície terrestre de qualquer forma, como chuva, granizo, orvalho, neve ou geada. Sua formação está ligada à ascensão das massas de ar, que pode ser devida aos seguintes fatores: convecção térmica, relevo e ação frontal de massas.

Em uma bacia hidrográfica, a cobertura florestal possui uma estreita relação com o ciclo hidrológico, interferindo no movimento da água em vários compartimentos do sistema, inclusive nas saídas para a atmosfera e para os rios (Figura 1). A quantidade de 
água de chuva que atinge o solo é denominada precipitação efetiva, que é a soma da precipitação interna e do escoamento pelo tronco.

A precipitação efetiva é a responsável pela água do solo, pela absorção através das raízes, pela transpiração das plantas e, também, pela alimentação dos rios.

A precipitação interna é a chuva que atinge o piso florestal, incluindo gotas que passam diretamente pelas aberturas entre as copas e gotas que respigam do dossel.

A fração da chuva que é retida temporariamente pelas copas juntamente com aquela que atinge diretamente os troncos e que posteriormente escoam pelo tronco das árvores, chegando ao solo, é denominada escoamento pelo tronco.

As precipitações em aberto podem ser mensuradas por meio de pluviômetros ou pluviógrafos. Na mata, a água interceptada pela vegetação e que escoa pelo tronco pode ser mensurada por coletores arbóreos constituídos por espuma expansiva de poliuretano.

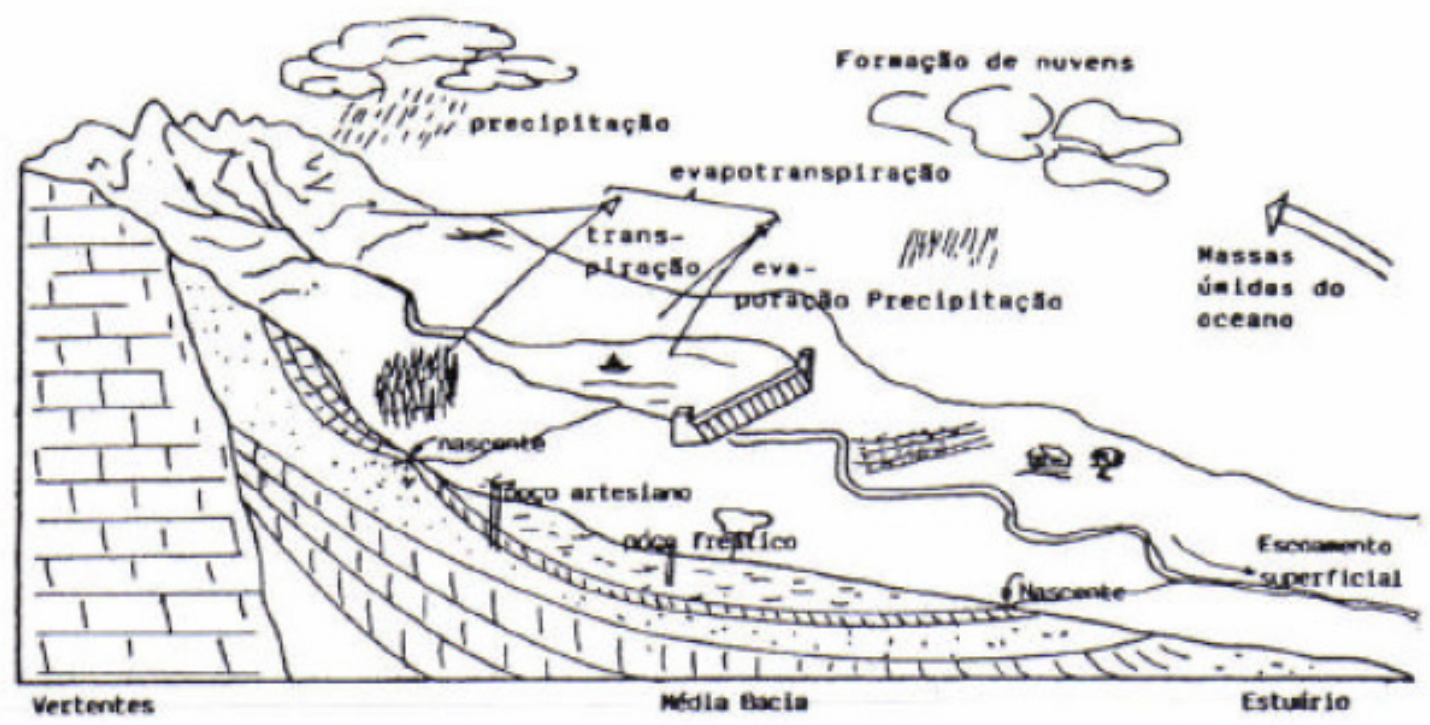

Figura 1: Representação esquemática dos processos hidrológicos envolvidos no balanço hídrico de uma bacia hidrográfica.

\section{Objetivo}

O objetivo deste trabalho foi avaliar a relação entre a área basal e a precipitação efetiva de água de chuva em um fragmento florestal remanescente de Mata Atlântica, Reserva Florestal e Ecológica Mata do Paraíso, localizada no Município de Viçosa, Zona da Mata do Estado de Minas Gerais. 


\section{Metodologia}

No período um ano, foram medidos os escoamentos pelo tronco das árvores, precipitação interna e em aberto em três parcelas experimentais demarcadas no interior da floresta, com $625 \mathrm{~m}^{2}$ de área cada, totalizando 15 coletas no período chuvoso que compreendeu de Janeiro à Maio e Outubro a Dezembro de 2007 e quatro coletas no período de estiagem, totalizando 19 coletas. No interior de cada parcela descrita acima, foi demarcada uma sub-parcela de $100 \mathrm{~m}^{2}$ de área utilizada para a determinação de escoamento pelo tronco das arvores situadas no seu interior com DAP $>5 \mathrm{~cm}$. Para essa medição, foram instalados dispositivos de espuma de poliuretano em todas as árvores com o DAP esperado. Os CAP dessas árvores foram utilizados para calcular a área basal de cada parcela.

Para determinação da precipitação interna, foram distribuídos sistematicamente, a cada $5 \mathrm{~m}, 25$ pluviômetros com abertura de $8 \mathrm{~cm}$ de diâmetro em cada parcela do experimento, cobrindo toda sua área.

A precipitação efetiva foi calculada somando-se o escoamento pelo tronco com a média da precipitação interna.

Para a precipitação em aberto foi instalado um pluviômetro de $15 \mathrm{~cm}$ de diâmetro próximo à área de medição da vazão do Córrego Santa Catarina, principal córrego da micro bacia estudada. As medições da vazão foram feitas após cada evento de chuva ocorrido no período de estudo.

\section{Resultados}

Calculando-se a média da precipitação efetiva das chuvas nesse período, não se pode verificar uma relação direta entre a área basal das parcelas e a precipitação efetiva. Para as parcelas 1, 2, 3 foi encontrado uma área basal de 2,2087 $\mathrm{m}^{2} ; 1,3293 \mathrm{~m}^{2} ; 3,7721 \mathrm{~m}^{2}$ respectivamente, e a precipitação efetiva nas três parcelas foram: $62,5 \mathrm{~mm} ; 58,8 \mathrm{~mm}$; $61,1 \mathrm{~mm}$ respectivamente.

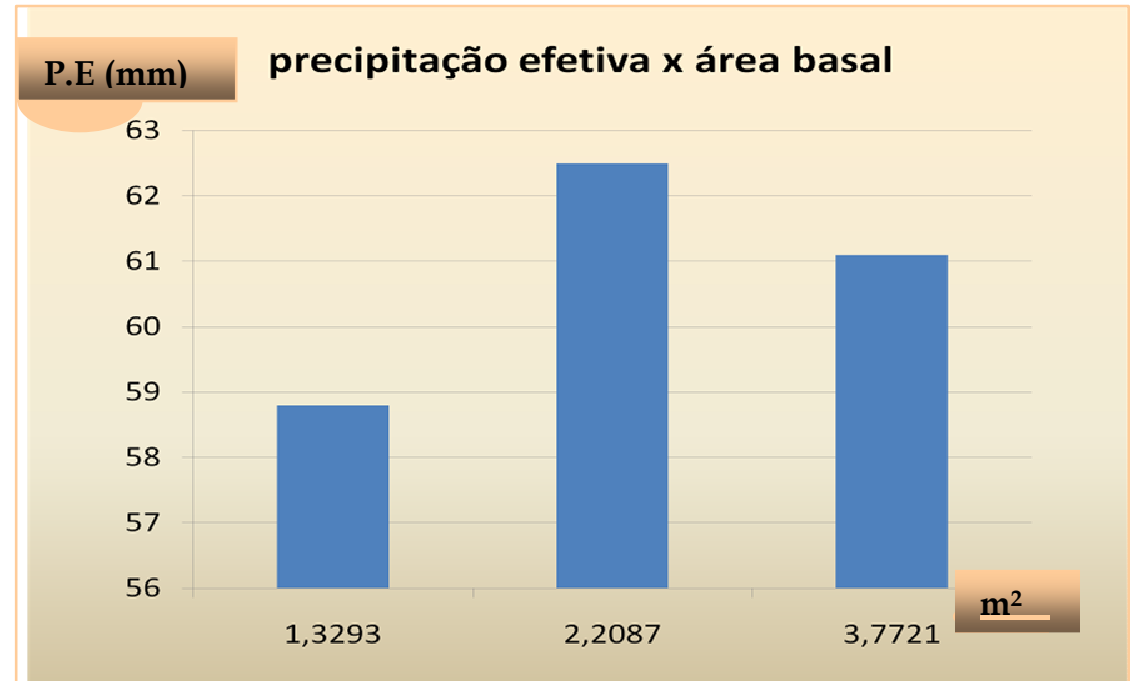

Figura 2: Precipitação Efetiva (P.E) e a Área Basal $\left(\mathrm{m}^{2}\right)$ na Reserva Florestal Mata do

Paraíso,Viçosa-MG, 2007. 


\section{Conclusão}

De acordo com os resultados observados, conclui-se que não há uma relação direta entre a precipitação efetiva à área basal das parcelas estudadas no período avaliado.

\section{Agradecimentos}

Os autores agradecem a Fundação de Amparo a Pesquisa do Estado de Minas Gerais, FAPEMIG, pelo apoio financeiro na pesquisa e pelo apoio para a ida ao SERHIDRO.

\section{Referencias Bibliográficas}

Alvarenga, A. P. Avaliação Inicial da Recuperação de Mata Ciliar em Nascentes. Dissertação (Mestrado em Ciência Florestal). Universidade Federal de Lavras, 2004. Lavras, MG. 175 p.

BRASIL. Lei 9.433/97, 8 jan.1997. Institui a Política Nacional de Recursos Hídricos e cria o Sistema Nacional de Gerenciamento dos Recursos Hídricos. Brasília: Ministério do Meio Ambiente /Secretaria de Recursos Hídricos. 1997.

CASTRO, P. S. e. Influência da cobertura florestal na qualidade da água em duas bacias hidrográficas na região de Viçosa, MG. 107 p. Dissertação (Mestrado em Engenharia Florestal) ESALQ, Piracicaba, SP, 1980.

DIAS, H.C.T. et al. Proteção de Nascentes. Brasília: SENAR, coleção 103, 80p., 2006.

OLERIANO, E. S.; DIAS, H.C.T. A dinâmica da água em microbacias hidrográficas reflorestadas com eucalipto. In: Anais I Seminário de Recursos Hídricos da Bacia Hidrográfica do Paraíba do Sul: o Eucalipto e o Ciclo Hidrológico, Taubaté, Brasil, 07-09 novembro 2007, IPABHi, p. 215-222.

OSAKI, F. Microbacias - Práticas de Conservação de solos. Curitiba - Paraná: 1994. 603p.

PAIVA, K. W. N. Perdas de solo e água em função da porcentagem de cobertura de solo e da energia única da precipitação. 1999. 66f. Dissertação (Mestrado em Engenharia Agrícola) Universidade Federal de Viçosa. Viçosa, MG.

PLANO NACIONAL DE EXTENSÃO UNIVERSITÁRIA. Fórum de Pró-Reitores de Extensão das Universidades Públicas Brasileiras, Natal - RN, 1998. 55p.

PLANO NACIONAL DE RECURSOS HÍDRICOS. Panorama e estado dos recursos hídricos do Brasil: Volume 1 / Ministério do Meio Ambiente, Secretaria de Recursos Hídricos. Brasília: MMA, 2006. v.4.

PRUSKI, F. F. Análises de precipitações extremas e de escoamento superficial, para áreas agrícolas, da região Oeste do Paraná. 1990. 109f.. Dissertação (Mestrado em Engenharia Agrícola) Universidade Federal de Viçosa. Viçosa, MG.

PRUSKI, F. F.; BRANDÃO, V. S.; SILVA, D.D. Escoamento superficial., Viçosa - MG: Editora UFV, 2003. $88 \mathrm{p}$ 
ROMANOVSKI, Z. Morfologia e aspectos hidrológicos da Microbacia Rua Nova, Viçosa, MG, para fins de manejo. 84 p. Dissertação (Mestrado em Ciência Florestal). Universidade Federal de Viçosa - UFV, Viçosa, MG, 2001.

SALIM NETO, S.C. Levantamento Preliminar das Nascentes de um trecho da Bacia do Rio Turvo. Dissertação (Monografia Engenharia Florestal). Universidade Federal de Viçosa, 2003. Viçosa, MG. 39p.

SANTANA, D. P. Manejo Integrado de Bacias Hidrográficas. Sete Lagoas:Embrapa Milho e Sorgo, Documentos, 30. ISSN 1518-4277, Dez. 2003, 63p.Disponível em: < www.cnpms.embrapa.br/publicacoes/publica/docume30.pdf >.Acesso em: 23 out. 2008.

SILVA, J. M. A. Modelo Hidrológico para o cálculo do balanço hídrico e obtenção do hidrograma de escoamento superficial em Bacias Hidrográficas: desenvolvimento e aplicação. 2002. 137f. Tese (Doutorado em Engenharia Agrícola). Universidade Federal de Viçosa. Viçosa, MG.

VALENTE, F. O.; GOMES, M. A. Conservação de Nascentes: hidrologia e manejo de bacias hidrográficas de cabeceiras. 2005. 210f. Editora Aprenda Fácil. Viçosa, MG.

VILAR, M. B. Escoamento superficial de água de chuva em área de contribuição de nascentes. 46 p. Dissertação (Monografia Engenharia Florestal). Universidade Federal de Viçosa. Viçosa - MG, 2007. 